\title{
A cellulase-supported two-phase in situ system for enhanced biosynthesis of paclitaxel in Taxus $\times$ media hairy roots
}

\author{
K. Sykłowska-Baranek ${ }^{1}$ D $\cdot$ K. Szala ${ }^{1} \cdot$ M. Pilarek ${ }^{2}$ (D) R. Orzechowski ${ }^{1,2} \cdot$ A. Pietrosiuk $^{1}$ (D)
}

Received: 16 February 2018 / Revised: 10 October 2018 / Accepted: 18 October 2018 / Published online: 30 October 2018

(c) The Author(s) 2018

\begin{abstract}
The effectiveness of two liquid-phase culture systems, in situ supported with perfluorodecalin (PFD), and elicited with methyl jasmonate $(100 \mu \mathrm{M})$ and sodium nitroprusside $(10 \mu \mathrm{M})$ (spiked with L-phenylalanine $(100 \mu \mathrm{M})$ and sucrose $(30 \mathrm{~g} / \mathrm{l})$ feeding), and additionally combined with cellulolytic enzyme application (Cellulase or Viscozyme ${ }^{\circledR} \mathrm{L}$ at doses $0.01 \%, 0.1 \%, 0.5 \%$ or $1 \%$ ), was investigated on the enhancement of paclitaxel release in Taxus $\times$ media harbouring taxadiene synthase transgene hairy root cultures. Neither elicitation nor in situ application of PFD significantly had an effect on root growth until enzyme addition; however, the hairy root response to the culture conditions varied depending on enzyme type and dosage. The highest paclitaxel total yield (intracellular + extracellular) was determined in the one-phase elicited culture systems without enzymes and amounted to $264.2 \mu \mathrm{g} / \mathrm{flask}(1434.9 \pm 516.6 \mu \mathrm{g} / \mathrm{g} \mathrm{DW}$ ) and $29.6 \mu \mathrm{g} / \mathrm{flask}$ in root biomass and medium phase, respectively. Although the application of cellulolytic enzymes did not enhance the total paclitaxel production, they intensified paclitaxel release in a dose-depending manner. Among two examined cellulolytic enzyme treatments, Viscozyme ${ }^{\circledR} \mathrm{L}$ addition caused the highest paclitaxel release up to $59 \%$ of its total content when used at a concentration of $0.01 \%$. Whereas in two-phase in situ systems, the combination of Viscozyme ${ }^{\circledR} \mathrm{L}$ at dosage of $0.5 \%$ and PFD-aerated, resulted in the highest extracellular paclitaxel concentration up to $20 \%$.
\end{abstract}

Keywords Taxus $\cdot$ In vitro paclitaxel release $\cdot$ Elicitation $\cdot$ Hairy roots $\cdot$ Perfluorodecalin

\section{Introduction}

Since the discovery of paclitaxel's potential as an anti-cancer drug in the 1970s enormous efforts have been undertaken to provide a significantly increased supply of this compound, as well as derivatives or intermediates of taxane-based plant

Communicated by M. Capuana.

Electronic supplementary material The online version of this article (https://doi.org/10.1007/s11738-018-2777-6) contains supplementary material, which is available to authorized users.

\section{K. Sykłowska-Baranek}

katarzyna.syklowska-baranek@wum.edu.pl

1 Department of Pharmaceutical Biology and Medicinal Plant Biotechnology, Faculty of Pharmacy with the Laboratory Medicine Division, Medical University of Warsaw, 1 Banacha Str, 02-097 Warsaw, Poland

2 Biotechnology and Bioprocess Engineering Division, Faculty of Chemical and Process Engineering, Warsaw University of Technology, 1 Waryńskiego, 00-645 Warsaw, Poland secondary metabolites (Expósito et al. 2009 and references therein).

Besides classical methods based on chemical synthesis (de novo or based on the molecules of intermediate products), biotechnological methods have been harnessed to meet the increasing pharmaceutical demand for paclitaxel and its derivatives (Vongpaseuth and Roberts 2007; SabaterJara et al. 2010; Onrubia et al. 2013a; Cusido et al. 2014). Screening for high-producing cell lines, targeted modification of culture conditions, as well as bioengineering-based support and modification of culture systems led to scaling-up of biotechnological methods for paclitaxel production and finally to their commercialization (Frense 2007; Wilson and Roberts 2012; Nosov 2012). However, considerable variability was observed in the case of Taxus spp. cell cultures, in relation to the growth rate of biomass, as well as the capability for paclitaxel production and its extracellular secretion, what translates into the instability of culture system recognized as one of the most vital problems observed in bioprocesses focused on taxane production (Ketchum et al. 1999; Kim et al. 2005; Vongpaseuth and Roberts 2007; Patil 
et al. 2013). Optimization of taxane biotechnological production, and paclitaxel in particular, includes modifications of in vitro culture conditions or development of the culture system which both could be favourable for the extracellular release of this bioproduct molecules in their native form with biological activity retained. In this respect, culture systems based on in situ product removal techniques have been reported to be an efficient strategy for the enhancement of secondary metabolite production (Cai et al. 2012; Malik et al. 2013). The hairy root cultures, due to their low requirements towards culture conditions and genetic stability, are widely considered to be efficient biological systems for producing a range of valuable bioactive compounds with therapeutic, as well as industrial applicability (Guillon et al. 2006a, b; Chandra and Chandra 2011; Zhou et al. 2011; Talano et al. 2012). Moreover, the enhancement of targeted biocompounds' release from the plant cells is believed to contribute to the reduction of scaling-up costs by facilitating product recovery and the simultaneous avoidance of detrimental of bioproduct biosynthesis feedback inhibition (Malik et al. 2013).

Results of the first studies on elucidation of subcellular localization of paclitaxel molecules and other taxanes indicated that their biosynthesis took place mainly in the vascular cambium region, and outer phloem of the inner bark as well, and that taxane molecules are subsequently deposited in the xylem (Strobel et al. 1993). A little later, the application of cryotechniques allowed to demonstrate that paclitaxel is almost exclusively present in the cell walls of some tissues, as phloem, vascular cambium and xylem (Russin et al. 1995). Further Choi et al. (2001), using the immunocytochemical method and laser scanning microscopy analysis revealed that in $T$. chinensis cell suspension cultures the majority of paclitaxel was found in cell walls. Moreover, the same authors reported the rise in paclitaxel concentration in the cell wall from 42.2 to $54.8 \%$ if determined on days 21 and 42, respectively, while paclitaxel levels decreased in plastids and endoplasmic reticulum simultaneously. However, later investigations on paclitaxel intra-cellular transport in T. baccata cell suspension cultures indicated that only $20 \%$ of the absorbed compound was found in cell walls, while $80 \%$ of this secondary metabolite was in the protoplast, which suggested deposition of paclitaxel molecules in vacuoles (Fornalè et al. 2002).

Taking into consideration that the most of the paclitaxel molecules could be accumulated inside the structure of cell walls, the basic aim of current studies was to elaborate the in situ technique of $T . \times$ media's hairy roots in vitro culture, which would enhance extracellular release of paclitaxel from integrated root biomass into the culture medium. The suitability of combination of cellulolytic enzymes, pure cellulase (from Trichoderma reesei) or multi-carbohydrases cocktail (Viscozyme ${ }^{\circledR} \mathrm{L}$ ), as agents potentially enhancing extracellular release of paclitaxel, has been tested and discussed. Additionally, the studied in vitro elicited cultures have been performed in a liquid-liquid culture system in which the aqueous phase of culture medium was combined with a layer of a hydrophobic liquid phase of perfluorinated compound for in situ extraction of paclitaxel released from root biomass.

To the best of our knowledge, the presented approach is an original integrated in situ bioprocess for the simultaneous chemically stimulated enhancing of paclitaxel released from yew's biomass and cell-safe extraction of the bioproduct performed in exactly the same culture system and that such methodology has not been proposed in the literature in the field up to now.

\section{Materials and methods}

\section{Hairy root cultures}

The Taxus $\times$ media hairy root line ATMA harbouring the taxadiene synthase (TXS) gene was used in this study. This line was obtained by the transformation carried out using the $\mathrm{C} 58 \mathrm{C} 1$ strain of Agrobacterium tumefaciens carrying the plasmid RiA4 of $A$. rhizogenes and the binary plasmid pCAMBIA-TXS-His, harbouring the TXS gene of T. baccata (GenBank accession: AY424738), under the control of the 35S CaMV promoter, and the hygromycin phosphotransferase gene (hptII) as a resistance marker (SykłowskaBaranek et al. 2015b). The hairy roots were subcultured routinely every 4 weeks in $250 \mathrm{ml}$ Erlenmeyer flasks containing $35 \mathrm{ml}$ of hormone-free DCR-M medium (SyklowskaBaranek et al. 2009). The cultures were maintained at $25 \pm 1{ }^{\circ} \mathrm{C}$ in the dark on an INFORS AG TR 250 shaker (Switzerland) at $105 \mathrm{rpm}$.

\section{Experimental procedures}

The cultures of 28-day-old hairy roots growing in $250 \mathrm{ml}$ Erlenmeyer flasks containing $35 \mathrm{ml}$ of DCR-M medium were subjected for all experiments. The root inoculum weight amounted to $0.5 \pm 0.05 \mathrm{~g}$. In control cultures the hairy roots grew in DCR-M medium without any supplementation through 42 days. The hairy roots were subjected to the following treatments: (i) supplementation with elicitors: methyl jasmonate (MJ; $100 \mu \mathrm{M}$, Sigma-Aldrich), sodium nitroprusside (SNP, $10 \mu \mathrm{M}$, Sigma-Aldrich) and precursor: L-phenylalanine (100 $\mu \mathrm{M}$, Sigma-Aldrich), with additional sucrose (30 g/l, Avantor Performance Materials Poland SA), called throughout the text as elicitor feeding; (ii) supplementation with elicitors and enzymes: Cellulase from Trichoderma reesei (Sigma-Aldrich) at concentrations of $0.01 \%, 0.1 \%, 0.5 \%$ and $1 \%$ or Viscozyme ${ }^{\circledR} \mathrm{L}$ from 
Aspergillus sp.—a multi-enzyme complex containing a wide range of carbohydrases, including arabanase, cellulase, $\beta$-glucanase, hemicellulase and xylanase (Sigma-Aldrich) at concentrations of $0.01 \%, 0.1 \%, 0.5 \%$ and $1 \%$; (iii) supplementation with perfluorodecalin (PFD), aerated or degassed without elicitors and enzymes; (iv) supplementation with PFD aerated or degassed and elicitors; (v) supplementation with PFD aerated or degassed and elicitors and enzymes as mentioned above. The amount of MJ, sodium nitroprusside, L-phenylalanine and sucrose has been given as the final concentration in the medium. The scheme of experiments is presented in Table $1 \mathrm{~S}$.

Perfluorodecalin $\left(\mathrm{C}_{10} \mathrm{~F}_{18} ; 98 \%\right.$ equimolar mixture of cis-/trans- isomers; ABCR GmbH \& Co. KG, Karlsruhe, Germany), the synthetic perfluorinated analog of decalin, was used in experiments. To ensure aseptic conditions and PFD-degassed, PFD was autoclaved at $121{ }^{\circ} \mathrm{C}$ for $20 \mathrm{~min}$. To obtain the PFD-aerated, it was aseptically saturated with atmospheric air for $15 \mathrm{~min}$. according to the procedure described previously (Pilarek and Szewczyk 2008). Afterwards, $20 \mathrm{ml}$ of PFD, degassed or aerated, was added to $35 \mathrm{ml}$ of sterile culture medium. PFD was applied to the flasks on the 14th day of culture. After addition of PFD to the medium, all flasks were closed with tightly squeezed aluminum caps.

At each time point the roots from three flasks were harvested. Roots were then gently pressed on filter paper to remove excess medium and their fresh weight (FW) was recorded as well as dry weight (DW) after lyophilization. The fresh biomass increase was expressed as a ratio of final weight to initial weight. Roots and liquids from collected samples were separated using a Büchner funnel.

\section{Cell viability assay}

The cell viability was determined with fluorescein diacetate (FDA) according to the method described by Duncan and Widholm (1990). The five to twelve roots from each treatment were taken for viability determination. After $30 \mathrm{~min}$. incubation with $0.02 \%$ FDA, the roots were observed under Zeiss microscope Discovery V12 Stereo using filter 38 (excitation/emission: 450-490-550 nm) and photographed using Canon IS-3 DLX camera. The viability of root cells and the integrity of root tissues were estimated. The widely stained green regions were related to the FDA-stained live cells.

\section{Chemical analysis}

The content of paclitaxel was determined in the powdered dry tissue of hairy roots, as well as in medium and PFD samples. The procedure applied for chemical analysis was described earlier by Sykłowska-Baranek et al. (2015b). Briefly, prior to extraction, the phases of medium and
PFD were carefully separated. The PFD phase was directly washed twice with methanol (Avantor Performance Materials Poland SA). These collected extracts were combined and evaporated to dryness under reduced pressure and subjected for HPLC-DAD analysis. The samples of roots and the aqueous phase were cleaned using the SPE (Solid Phase Extraction) method elaborated by Theodoridis et al. (1998a). All samples were re-dissolved in $100 \% \mathrm{MeOH}(400 \mu \mathrm{l})$ and 20 $\mu \mathrm{l}$ was subjected to HPLC-DAD using the DIONEX (USA) system with a UVD 340 S diode array detector and an automated sample injector (ASI-100). For compound separation, a Kinetex (Phenomenex, USA) $100 \times 4.60 \mathrm{~mm}$ column was eluted employing the gradient program as described by Theodoridis et al. (1998b) with some modifications. The mobile phase was: A-ammonium acetate $0.05 \mathrm{M}$ : acetonitrile ( $7: 3$ w/w), B-ammonium acetate $0.05 \mathrm{M}$ : acetonitrile $(1: 9 \mathrm{w} / \mathrm{w})$. The following gradient program was used: 0-15 min. A $100 \%, 15-20 \mathrm{~min}$. A $66 \%-\mathrm{B} 34 \%, 20-21 \mathrm{~min}$. A 100\%. The flow rate was $0.8 \mathrm{ml} / \mathrm{min}$. The DAD spectrophotometer was set at a wavelength range of 215-275 $\mathrm{nm}$. The taxanes were identified and quantified at $227 \mathrm{~nm}$. The peaks were assigned by spiking the samples with the standards and comparing the retention times and UV spectra. The sample peak areas were integrated by comparison with an external standard calibration curve. A calibration curve was constructed with linear least square regression analysis using Chromeleon PCS 1 software.

The standard compound was produced by CHOMADEX (USA) and purchased from LCG Standards (Poland). All chemicals were of HPLC-grade and purchased from SigmaAldrich (Poland).

All experiments were performed in triplicate. The statistical significance between means was assessed using analysis of variance (ANOVA) and Tukey's multiple range test. For pairwise analysis Student's $t$ test was used. A probability of $p=0.05$ was considered significant.

\section{Results and discussion}

\section{The influence of culture conditions on hairy root biomass increase}

One of the essential aims of current investigations was to develop culture conditions which would allow to maximize the paclitaxel release without the loss of the root viability and the integrity of root tissue. On the basis of previous study (Sykłowska-Baranek et al. 2015b), the PFD phases were applied on the 14th day of cultivation as the optimal time point for ATMA hairy root growth. The time course of fresh and dry biomass growth (expressed as $g$ of fresh or dry weight/flask) demonstrated the biomass accumulation in control cultures till the end of culture, although the 
beginning of the stationary phase was observed on day 35 (Fig. 1a, b). Under the conditions of the current experiment the highest hairy root fresh biomass increase (2.1fold \pm 0.20 ) was determined after 2-week cultivation carried out in the presence of PFD-aerated without elicitors and enzymes (Fig. 1a). In the cultures without enzyme supplementation, the lowest and statistically significant $(p=0.05)$ rates of root growth were noted in cultures supported with PFD-degassed or PFD-degassed with elicitors, 1.4- and 1.2fold, respectively.

Up to now the higher Taxus spp. hairy root growth rates were reported, up to 19.3 -fold for T. cuspidata hairy roots within 2 months of culture (Kim et al. 2009) and up to 5.9fold for T. sumatrana hairy roots within 40 days of culture (Chang et al. 2017). The lower growth rates achieved by the ATMA hairy root line under conditions of current investigation could be attributed to the fact that each hairy root represents different clone as the incorporation of T-DNA is random and significantly influences the hairy root growth capacities as well as their potential for secondary metabolite production (Bulgakov 2008; Chandra 2012).

The effect of enzyme application to the medium on root biomass accumulation differed depending on enzyme type and dose and was statistically significant $(p=0.05)$ (Fig. 1b, d). In general the root growth rates observed in culture variants containing Cellulase were higher than those in cultures supplemented with Viscozyme ${ }^{\circledR}$ L. The enzyme addition to the cultures elicited, but without PFD phases, the root biomass accumulation was suppressed in comparison to the cultures without enzymes but with PFD phases (1.8fold) (Fig. 1). The addition of Cellulase to the elicited cultures supported with PFD-degassed stimulated the biomass increase in comparison to the equivalent treatments but without this enzyme, while Viscozyme ${ }^{\circledR} \mathrm{L}$ application caused its decrease (Fig. 1). In elicited cultures supported with PFD-aerated, application of Cellulase or Viscozyme ${ }^{\circledR} \mathrm{L}$ at doses $0.01 \%$ or $1 \%$ diminished root growth in relation to the comparable variant without this enzyme, while at concentrations of $0.5 \%$ or $1 \%$ the root growth enhancement was noted (Fig. 1). The addition of Cellulase to the cultures carried out with PFD-degassed and elicitors resulted in significant $(p=0.05)$ biomass accumulation in comparison to the similar culture variant performed without Cellulase. However, the supplementation of the media with enzymes resulted in accumulation of cell debris, the integrity of root tissues were maintained and they remained alive which was confirmed through FDA staining (Figs. 2, 4).

As it was previously reported (Sykłowska-Baranek et al. 2015b) the addition of PFD-aerated depressed to the highest extent the root growth followed by one-phase and twophase systems supplemented with the elicitor that is MJ. The effect of applied herein mixture of elicitors, which has been found to be the most favourable for paclitaxel production in former investigations (Sykłowska-Baranek et al. 2015a), slightly affected ATMA line hairy root growth which corroborates previous results. The application of the mixture of elicitors performed in this study caused even augmentation (although not statistically significant at $p=0.05$ ) in root growth, which was 1.8 -fold versus 1.7 -fold in untreated control cultures as compared on the 42nd day of culture, that is 2 weeks after elicitation. This biomass increase could be achieved thanks to additional sucrose feeding done together with the elicitor mixture application on the 14th day of cultivation as similar phenomena were reported in $T$. chinensis cell suspension cultures, although after maltose addition (Choi et al. 2001). In the current study, only medium supplementation with enzymes, Cellulase or Viscozyme ${ }^{\circledR} \mathrm{L}$, in the elicited cultures suppressed root growth, which could be due to their acting as a second stressor. Nevertheless, the culture supporting PFD phases diminished the harmful impact of elicitation and enzyme treatment; however, this effect depended on the culture variant (Fig. 1). These observations correspond to the results of previous investigations (Sykłowska-Baranek et al. 2015b), where root growth in PFD supported cultures after elicitation with MJ was higher than in that elicited without perfluorinated phases, degassed or aerated. The results of current study are also consistent with data published by Patil et al. (2014) which indicates that cell growth in suspension cultures of $T$. cuspidata upon elicitation with MJ could be attributed to slowed down cell cycle progression, an increase in G0/G1 phase cells and a reduced number of actively dividing cells rather than necrosis.

Up to date in Taxus spp. in vitro cultures, for the in situ extraction of paclitaxel and other taxanes a XAD-4 nonionic exchange resin (Kwon et al. 1998) or organic solvents were used improving paclitaxel yield up to $70 \%$ (Collins-Pavao et al. 1996), often when combined with elicitation (Zhang and Xu 2001; Wu and Lin 2003). The application of various organic solvents for in situ extraction in Taxus spp. cell cultures was reported to be remarkably harmful for cultivated cells (Malik et al. 2013 and references herein). It was demonstrated that such a deleterious effect resulted from abnormal mitosis and apoptosis (Xu et al. 2005) manifesting by the release of cytochrome c from mitochondria and inhibition of extracellular signal-regulated kinase-like MAPK (Cheng et al. 2008). The PFD two-phase system applied under conditions of current experiment appeared to be neutral or even beneficial for root viability due to their reported inertness and lack of toxicity in biological systems, as well as their high gas solubility enhancing cell, tissue and organ growth (Lowe 2002; Davey et al. 2005; Pilarek 2014). 
Fig. 1 Taxus $\times$ media hairy root fresh $(\mathbf{a}, \mathbf{b})$ and dry $(\mathbf{c}, \mathbf{d})$ biomass growth (expressed as $\mathrm{g} /$ flask) under various culture conditions. Values represent means \pm SD. Asterisk $(*)$ indicates statistically significant differences $(p=0.05)$ in relation to control while the same letters indicate statistically significant differences $(p=0.05)$ between non-enzyme and enzyme treatments
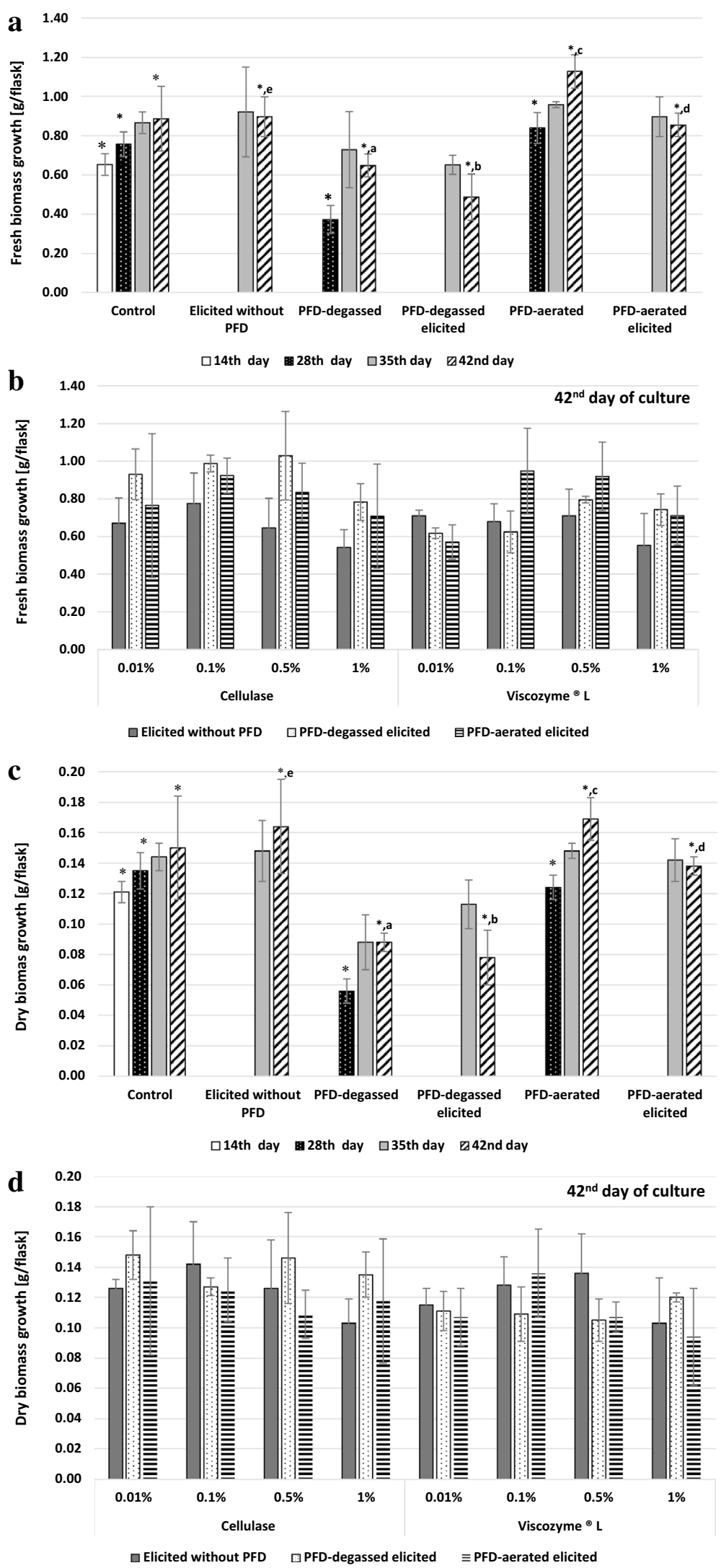

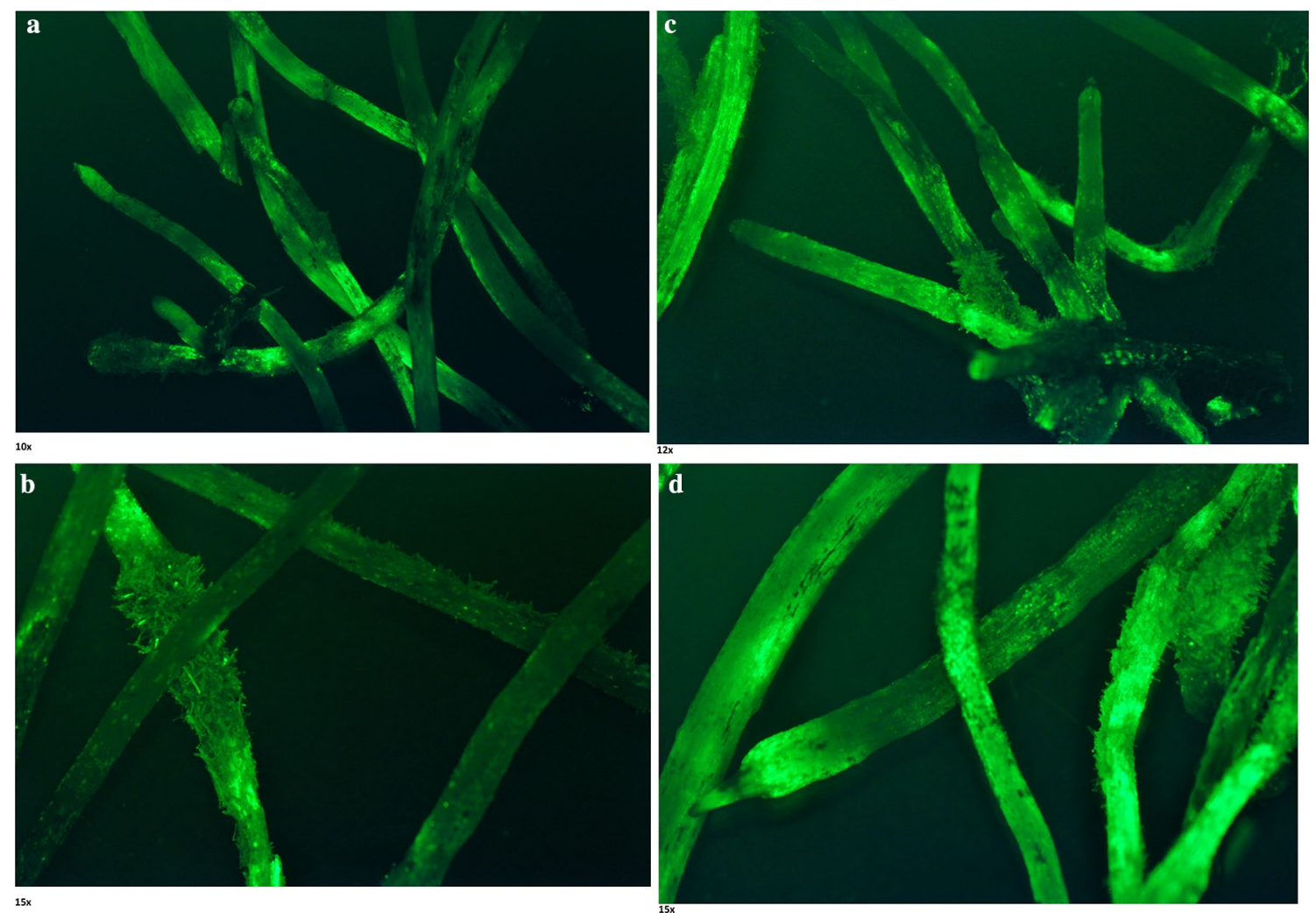

Fig. 2 The viability of Taxus $\times$ media hairy roots growing in liquid DCR-M medium in a control untreated cultures; $\mathbf{b}$ in elicited cultures without enzyme treatment and in the elicited cultures supplemented

\section{The influence of culture conditions on paclitaxel production}

In current study the earlier developed for Taxus $\times$ media hairy roots two-phase culture system supported with liquid PFD degassed or aerated added on the 14th day of culture as a gas carrier and in situ extractant was used (SykłowskaBaranek et al. 2015b). These culture systems were supplemented with a mixture of elicitors, precursor and sucrose on the 28th day of culture, which in previous investigations proved to be the most effective in the induction of paclitaxel biosynthesis (Sykłowska-Baranek et al. 2015a). On the 35th day of cultivation all elicited culture variants were fed with enzymes Cellulase or Viscozyme ${ }^{\circledR} \mathrm{L}$ to enhance paclitaxel and/or other taxanes' release.

As in the former experiments (Sykłowska-Baranek et al. 2015a, b) in cultures of ATMA hairy root line, also under conditions of this study hairy roots produced paclitaxel solely upon elicitation. No detectable amounts of paclitaxel were found in any of the PFD-phases. The highest paclitaxel yield, intracellular as well as extracellular, was determined in the elicited culture variant without PFD and enzymes and amounted to $264.2 \mu \mathrm{g}$ /flask $(1434.9 \pm 516.57 \mu \mathrm{g} / \mathrm{g} \mathrm{DW})$ and $29.63 \mu \mathrm{g} /$ flask in the root with: c $0.5 \%$ of Viscozyme ${ }^{\circledR} \mathrm{L}$ or $\mathbf{d} 0.5 \%$ of Cellulase. The widely stained green regions were related to the FDA-stained live cells (Photo. I. Rudnicki)

biomass and medium aqueous phase, respectively (Fig. 3; Table 1). In the elicited two phase culture systems, PFDaerated application significantly $(p=0.05)$ affected the paclitaxel content in the root biomass in comparison to the addition of PFD-degassed (Fig. 3; Table 1). Considerably higher extracellular amounts of paclitaxel were found in the enzyme-treated culture variants without PFD phases than in those supported with PFD, irrespectively, degassed or aerated (Fig. 3; 1S). When the results obtained within the same culture variants were considered, that is two phase culture systems supplemented with Cellulase or Viscozyme ${ }^{\circledR} \mathrm{L}$, it was revealed that in the presence of PFD-aerated the paclitaxel total yield (intra- and extracellular) was enhanced and, in addition this compound was more readily released to the medium than in PFD-degassed supported variants. Nevertheless, under conditions of this study paclitaxel was not found in PFD phases which is in opposition to the results reported earlier (SykłowskaBaranek et al. 2015b). This outcome could be attributed to the creation of complexes between paclitaxel and cell exudates occurring in the medium during cultivation like phenolics, proteins, sugars (Cai et al. 2012) (Fig. 4). Such complexation could hamper the transfer of targeted compound to the PFD phases. However, in some elicited 


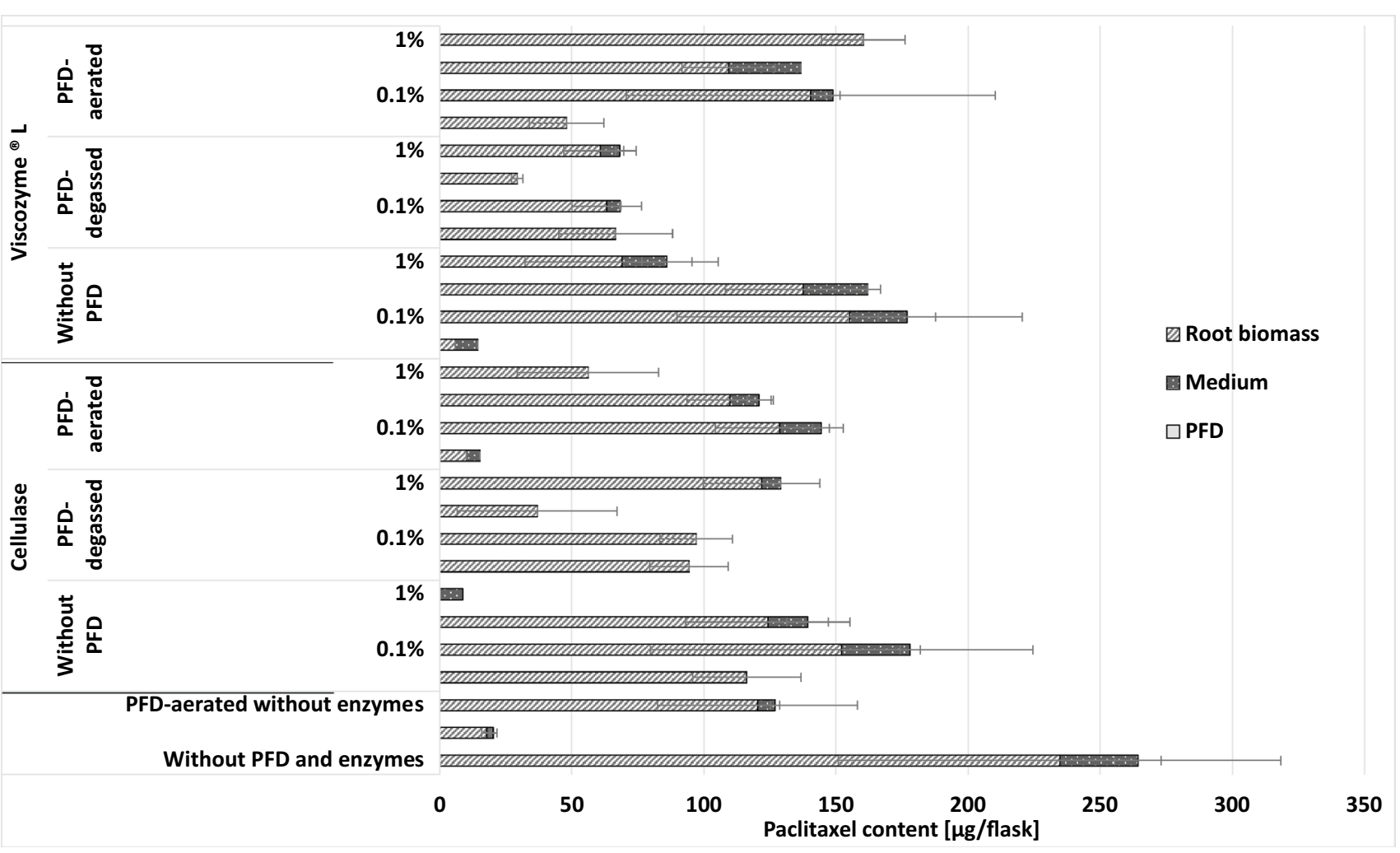

Fig. 3 Paclitaxel content [ $\mu \mathrm{g} /$ flask] detected in Taxus $\times$ media hairy roots growing in various modifications of elicited cultures

Table 1 Intracellular paclitaxel content $(\mu \mathrm{g} / \mathrm{g}$ DW) in hairy roots of Taxus $\times$ media cultivated in various modifications of elicited cultures

\begin{tabular}{|c|c|c|c|c|c|}
\hline \multicolumn{2}{|c|}{ Without PFD phase } & \multicolumn{2}{|l|}{ With PFD-degassed } & \multicolumn{2}{|c|}{ With PFD-aerated } \\
\hline 35 day & 42 day & 35 day & 42 day & 35 day & 42 day \\
\hline \multicolumn{6}{|c|}{ Culture systems without enzymes } \\
\hline $1047.7^{\mathrm{a}} \pm 217.47$ & $1434.9^{\mathrm{b}} \pm 516.57$ & $345.26^{\mathrm{a}, \mathrm{i}} \pm 279.88$ & $220 *$ & $759.14^{\mathrm{a}} \pm 95.73$ & $869.18^{\mathrm{b}, \mathrm{j}} \pm 251.73$ \\
\hline Type of enzyme & Concentration & Without PFD phase & & With PFD-degassed & With PFD-aerated \\
\hline \multicolumn{6}{|c|}{ Culture systems with addition of enzymes } \\
\hline \multirow[t]{4}{*}{ Cellulase } & $0.01 \%$ & $1168.07 \pm 318.82$ & & $1171.63^{\mathrm{i}} \pm 389.58$ & $112.11^{*}$ \\
\hline & $0.1 \%$ & $1041.34 \pm 413.99$ & & $991.67^{\mathrm{i}} \pm 164.16$ & $1031.17 \pm 114.35$ \\
\hline & $0.5 \%$ & $993.43^{c} \pm 160.25$ & & $328.68^{c} \pm 261.71$ & $1030.63^{c} \pm 263.91$ \\
\hline & $1 \%$ & 0 & & $1175.20^{\mathrm{d}, \mathrm{i}} \pm 209.4$ & $546.5^{\mathrm{d}, \mathrm{j}} \pm 366.28$ \\
\hline \multirow[t]{4}{*}{ Viscozyme ${ }^{\circledR} \mathrm{L}$} & $0.01 \%$ & $55.40^{*}$ & & $756.55^{\mathrm{e}, \mathrm{i}} \pm 305.95$ & $514.13^{\mathrm{e}, \mathrm{j}} \pm 164.78$ \\
\hline & $0.1 \%$ & $1178.96^{\mathrm{f}} \pm 309.76$ & & $679.34^{\mathrm{f}, \mathrm{i}} \pm 111.78$ & $993.37^{\mathrm{f}} \pm 311.73$ \\
\hline & $0.5 \%$ & $1016.19^{\mathrm{g}, \mathrm{h}} \pm 47.30$ & & $313.02^{\mathrm{g}} \pm 49.77$ & $1015.8^{\mathrm{g}, \mathrm{h}} \pm 110.26$ \\
\hline & $1 \%$ & $701.39^{\mathrm{b}} \pm 275.17$ & & $618.47^{\mathrm{i}} \pm 142.18$ & $1512.43 *$ \\
\hline
\end{tabular}

Values represents means of three replicates \pm SD. The same letters indicate means statistically different $(p=0.05)$. The asterisks indicate that a unique result of three replicates was obtained by HPLC analysis

culture variants an unknown taxane-like compound characterized by UV spectrum similar to that of paclitaxel was detected. This compound was found both in medium and PFD-phases (in the following culture variants: elicited simultaneously supplemented with enzymes and
PFD-aerated phase; elicited without enzymes but with PFD-aerated phase; in elicited without enzymes and PFD addition).

The intracellular content of paclitaxel determined under the conditions of the present study (Table 1) differed from 


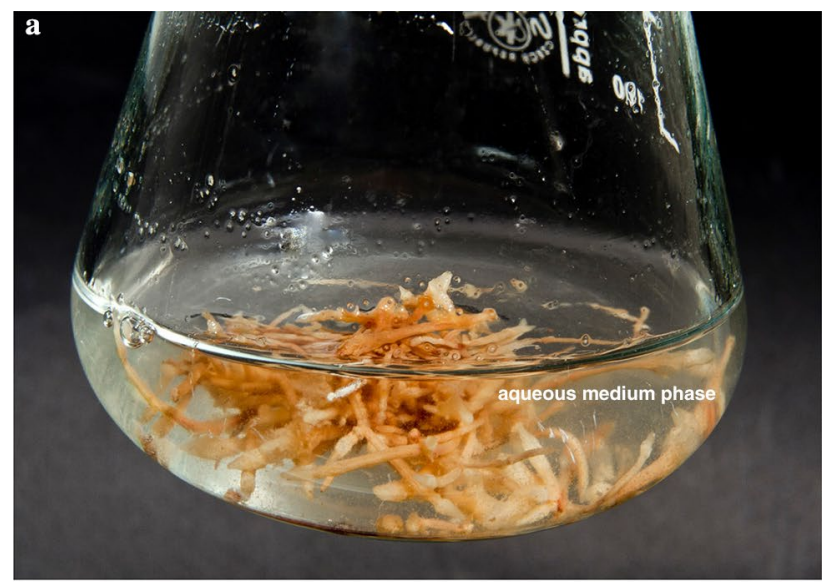

$1.5 x$

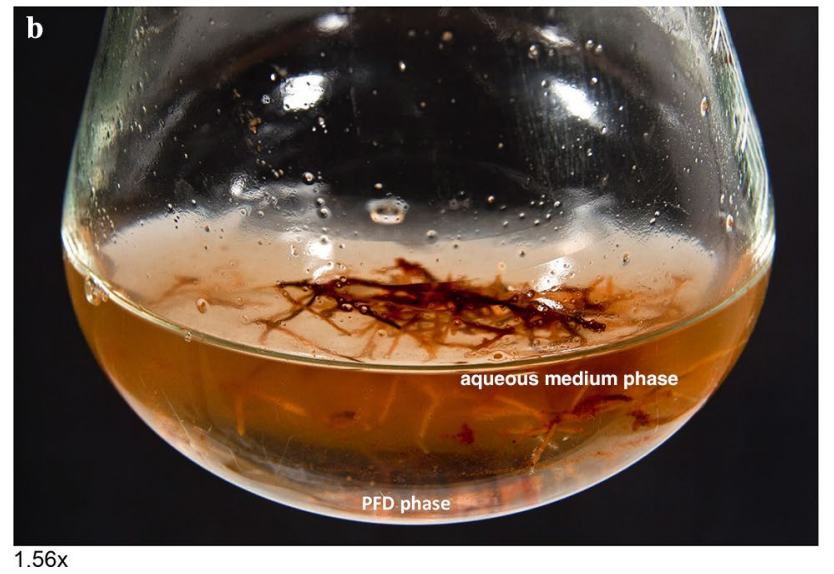

Fig. 4 Taxus $\times$ media hairy roots cultivated in DCR-M medium: a without any supplementation (control culture) on the 42nd day of culture; $\mathbf{b}$ with PFD-degassed and elicitors on the 42nd day of culture (Photo. I. Rudnicki)

those reported previously (Sykłowska-Baranek et al. 2015a, b) which could be attributed to a variability in paclitaxel levels reported in Taxus spp. long-term cell cultures ranging up to 6.9-fold in cell suspension cultures (Patil et al. 2012 and references therein; 2013). In current investigations that the highest paclitaxel release achieved 59\% of its total content was noted under $0.01 \%$ Viscozyme ${ }^{\circledR} \mathrm{L}$ treatment in culture variant without PFD phases, although the intra$(5.93 \mu \mathrm{g} /$ flask $)$ and extracellular $(8.52 \mu \mathrm{g} /$ flask $)$ paclitaxel content was here the lowest among all tested variants. In two-phase culture variants supplemented with enzymes, the highest paclitaxel release was determined under Viscozyme ${ }^{\circledR}$ L $0.5 \%$ and Cellulase $0.1 \%$ treatments (Fig. 3). Aoyagi et al. (2002) published results of the investigations on the applicability of enzyme-catalysed polysaccharide degradation technique for an enhancement of paclitaxel yield in cultures of $T$. cuspidata protoplasts. It turned out that the application of cellulase, pectinase and hemicellulose, alone or in a mutual combination, led to enhanced levels of paclitaxel found in the cell wall and/or between cell wall and cell membrane, which ranged from 30.5 to $35.1 \%$ for cells harvested in exponential and stationary growth phases, respectively. Moreover, the treatment of yew biomass with every single cellulolytic enzyme studied separately from others caused the increased yield of paclitaxel released from cells in the range from 40 to $65 \%$, while the application of the enzyme cocktail of all three regarded biocatalyzators resulted in even doubled levels of paclitaxel released from cells. Next, Roberts et al. (2003) presented the results of paclitaxel release from biomass of in vitro cultured $T$. canadensis cells with cellulase, pectolase and $0.5 \mathrm{M}$ mannitol. They have reported a positive impact of such modified culture environment on cell morphology which resulted in enhanced vitality of protoplasts. In the case of increasing level of extracellularly released paclitaxel, over threefold and twofold higher concentration of the bioproduct have been noted in unelicited culture and culture system subjected to elicitation with MJ, respectively, in relation to results of paclitaxel levels determined in the analogous culture systems without in situ performed enzymatic treatment of biomass.

The variable levels of extracellular paclitaxel content in various Taxus spp. culture systems could suggest the involvement of an active mechanism and/or non-energy dependent one engaged in paclitaxel transport (Naill et al. 2012). The existence of an ATP-dependent ABC transporter was postulated which was further confirmed by Sabater-Jara et al. (2014) describing taxane production in cell suspension cultures of $T$. $\times$ media harbournig TXS synthase gene of $T$. baccata. In this publication the authors observed 23 -fold enhanced expression of the $A B C$ gene under simultaneous elicitation with $\mathrm{MJ}$ and the application of randomly methylated- $\beta$-cyclodextrin (M- $\beta$-CD) in relation to the control and twofold in comparison to elicitation solely with MJ. This phenomena corresponded with significantly higher taxane excretion ranging from $45 \%$ in the control and $65 \%$ in cultures elicited solely with MJ up to $86 \%$ under combined elicitation with M- $\beta-C D$. High levels of extracellular paclitaxel content were also observed in previous examination performed in cell suspension cultures of $T$. $\times$ media harbouring TXS synthase gene, where release of taxanes to the culture medium upon MJ elicitation amounted up to $68.69 \%$ of its total content (Exposito et al. 2010) and even over 80\% (Onrubia et al. 2013b). The described above relatively high levels of extracellular paclitaxel were reported from cell suspension cultures of $T . \times$ media, while in previous investigations the release of paclitaxel in hairy root cultures ranged from nearly $2 \%$ when elicitation with SNP, MJ and L-phenylalanine was used (Sykłowska-Baranek et al. 2015a) and 22\% after application of MJ and PFD-aerated (SykłowskaBaranek et al. 2015b). The discrepancy in the potential for paclitaxel release between undifferentiated cell cultures and integrated hydroponically cultivated roots of $T . \times$ media 
were described also by Wickremesinhe and Arteca (1994, 1996). The authors reported very limited paclitaxel secretion (less than 10\%) from cells in suspension cultures and no paclitaxel or other taxanes release from roots, respectively. Although, there is no one way to improve the paclitaxel and other taxane output in in vitro cultures of various Taxus spp., as though it relies on many factors like the specimen which served as an explant donor, type of culture (callus, cell suspension, organs), culture conditions, elicitor/s and precursor/s feeding, in situ extraction, etc. (Expósito et al. 2009; Onrubia et al. 2013a; Sabater-Jara et al. 2010; Cusido et al. 2014).

The combined approach of elicitation and in situ extraction seems to be a very promising strategy in enhancing taxane production; however, in $T$. $\times$ media hairy root cultures further investigations are needed to develop the most suitable conditions for paclitaxel accumulation.

\section{Conclusions}

The data reported in this study demonstrated that most of the paclitaxel produced in hairy root cultures of $T . \times$ media were deposited intracellulary and the elicitation step was essential for inducing paclitaxel production. The addition of cell digesting enzymes applied under conditions of this work allowed to maintain root tissue integrity and intensified paclitaxel release in a dose-dependent manner, however did not enhances the total paclitaxel production. The comparison of corresponding culture variants revealed that Cellulase supplementation increased paclitaxel release in cultures without PFD phases and in PFD-aerated supported variants, at concentrations of $0.1 \%$ and $0.01-0.5 \%$, respectively. The Viscozyme ${ }^{\circledR}$ L addition caused the highest paclitaxel release up to $59 \%$ of its total content when used at concentration of $0.01 \%$ in culture variants without PFD phases, While in two-phase in situ systems, the combination of PFD-aerated and Viscozyme ${ }^{\circledR} \mathrm{L}$ at dosage of $0.5 \%$, resulted in the highest extracellular paclitaxel concentration up to $20 \%$. The application of Viscozyme ${ }^{\circledR} \mathrm{L}$ was more effective in paclitaxel release than Cellulase.

Author contribution Statement KSB-planning of the investigations, in situ application of PFD, HPLC UV-DAD analysis, elaboration of the results and preparation of the manuscript. KS - carrying out in vitro cultures in variants containing PFD-degassed and supplemented with enzymes at doses of $0.01 \%$, and $1 \%$ and PFD-aerated with supplementation with enzymes at dosages of $0.1 \%$ and $0.5 \%$; sample preparation for chemical investigations; elaboration of the results. MP - in situ application of PFD, results elaboration and discussion, critical reading of the manuscript. $\mathrm{RO}$ - carrying out in vitro cultures in variants containing
PFD-aerated and supplemented with enzymes at doses of $0.1 \%$, and $0.5 \%$; sample preparation for chemical investigations; elaboration of the results. AP-results elaboration and discussion, critical reading of the manuscript.

Acknowledgements This work was supported by the Statutory Budget [FW21/N/2017] of the Medical University of Warsaw.

Open Access This article is distributed under the terms of the Creative Commons Attribution 4.0 International License (http://creativeco mmons.org/licenses/by/4.0/), which permits unrestricted use, distribution, and reproduction in any medium, provided you give appropriate credit to the original author(s) and the source, provide a link to the Creative Commons license, and indicate if changes were made.

\section{References}

Aoyagi H, DiCosmo F, Tanaka H (2002) Efficient paclitaxel production using protoplasts isolated from cultured cells of Taxus cuspidata. Planta Med 68:420-424. https://doi.org/10.1055/s-2002-32082

Bulgakov VP (2008) Functions of rol genes in plant secondary metabolism. Biotechnol Adv 26:318-324. https://doi.org/10.1016/j.biote chadv.2008.03.001

Cai Z, Kastell A, Knorr D, Smetanska I (2012) Exudation: an expanding technique for continuous production and release of secondary metabolites from plant cell suspension and hairy root cultures. Plant Cell Rep 31:461-477. https://doi.org/10.1007/s0029 9-011-1165-0

Chandra S (2012) Natural plant genetic engineer Agrobacterium rhizogenes: role of T-DNA in plant secondary metabolism. Biotechnol Lett 34:407-415. https://doi.org/10.1007/s10529-011-0785-3

Chandra S, Chandra R (2011) Engineering secondary metabolite production in hairy roots. Phytochem Rev 10:371-395. https://doi. org/10.1007/s11101-011-9210-8

Chang S, Chen F, Chen Y, Tsay J, Chen J, Huang C, Lu W, Ho C (2017) Induction, culture, and taxane production of crown galls and hairy roots of Taxus sumatrana (Miq) de Laub. Taiwan J For Sci 32:283-303

Cheng J-S, Xu Q-M, Wu J-C, Yuan Y-J (2008) ERK-like MAPK signaling and cytochrome $\mathrm{c}$ response to oleic acid in two-liquid-phase suspension cultures of Taxus cuspidata.. Biochem Eng J 41:274 279. https://doi.org/10.1016/j.bej.2008.05.010

Choi HK, Kim SI, Song JY, Son JS, Hong SS, Durzan DJ, Lee HJ (2001) Localization of paclitaxel in suspension culture of Taxus chinensis. J Microbiol Biotechnol 11:458-462

Collins-Pavao M, Chin CK, Pedersen H (1996) Taxol partitioning in two-phase plant cell cultures of Taxus brevifolia. J Biotechnol 49:95-100. https://doi.org/10.1016/0168-1656(96)01525-8

Cusido RM, Onrubia M, Sabater-Jara AB, Moyano E, Bonfill M, Goossens A, Angeles Pedreño M, Palazon J (2014) A rational approach to improving the biotechnological production of taxanes in plant cell cultures of Taxus spp. Biotechnol Adv 32:1157-1167. https ://doi.org/10.1016/j.biotechadv.2014.03.002

Davey MR, An P, Power JB, Lowe KC (2005) Plant protoplast technology: current status. Acta Physiol Plant 27:117-129. https://doi. org/10.1007/s11738-005-0044-0

Duncan DR, Widholm JM (1990) Measurements of viability suitable for plant tissue cultures. In: Pollard JW (ed) Plant cell and tissue culture. Methods in molecular biology ${ }^{\mathrm{TM}}$, vol 6. Humana Press, Clifton, pp 29-37. https://doi.org/10.1385/0-89603-161-6:29 
Exposito O, Syklowska-Baranek K, Moyano E, Onrubia M, Bonfill M, Palazon J, Cusido RM (2010) Metabolic responses of Taxus media transformed cell cultures to the addition of methyl jasmonate. Biotechnol Prog 26:1145-1153. https://doi.org/10.1002/btpr.424

Expósito O, Bonfill M, Moyano E, Onrubia M, Mirjalili MH, Cusidó RM, Palazón J (2009) Biotechnological production of taxol and related taxoids: current state and prospects. Anticancer Agents Med Chem 9:109-121. https://doi.org/10.2174/187152009787047 761

Fornalè S, Degli D, Navia-Osorio A, Cusidò RM, Palazòn J, Piñol MT, Bagni N (2002) Taxol transport in Taxus baccata cell suspension cultures. Plant Physiol Biochem 40:81-88. https://doi. org/10.1016/S0981-9428(01)01332-8

Frense D (2007) Taxanes: perspectives for biotechnological production. Appl Microbiol 73:1233-1240. https://doi.org/10.1007/ s00253-006-0711-0

Guillon S, Trémouillaux-Guiller J, Pati PK, Rideau M, Gantet P (2006a) Harnessing the potential of hairy roots: dawn of a new era. Trends Biotechnol 24:403-409. https://doi.org/10.1016/j.tibte ch.2006.07.002

Guillon S, Trémouillaux-Guiller J, Pati PK, Rideau M, Gantet P (2006b) Hairy root research: recent scenario and exciting prospects. Curr Opin Plant Biol 9:341-346. https://doi.org/10.1016/j. pbi.2006.03.008

Ketchum RE, Gibson DM, Croteau RB, Shuler ML (1999) The kinetics of taxoid accumulation in cell suspension cultures of Taxus following elicitation with methyl jasmonate. Biotechnol Bioeng 62:97-105. https://10.1002/ (SICI)1097-0290(19990105)62:1<97::AID-BIT11>3.0.CO;2-C

Kim BJ, Gibson DM, Shuler ML (2005) Relationship of viability and apoptosis to taxol production in Taxus sp. suspension cultures elicited with methyl jasmonate. Biotechnol Prog 21:700-707. https:// doi.org/10.1021/bp050016z

Kim JA, Baek KH, Son YM, Son SH, Shin H (2009) Hairy root cultures of Taxus cuspidata for enhanced production of paclitaxel. $\mathbf{J}$ Korean Soc Appl Biol Chem 52:144-150. https://doi.org/10.3839/ jksabc.2009.027

Kwon IC, Yoo YJ, Lee JH, Hyun JO (1998) Enhancement of taxol production by in situ recovery of product. Process Biochem 33:7001-7707. https://doi.org/10.1016/S0032-9592(98)00037-5

Lowe KC (2002) Perfluorochemical respiratory gas carriers: benefits to cell culture systems. J Fluor Chem 118:19-26. https://doi. org/10.1016/S0022-1139(02)00200-2

Malik S, Hossein Mirjalili M, Fett-Neto AG, Mazzafera P, Bonfill M (2013) Living between two worlds: two-phase culture systems for producing plant secondary metabolites. Crit Rev Biotechnol 33:1-22. https://doi.org/10.3109/07388551.2012.659173

Naill MC, Kolewe ME, Roberts SC (2012) Paclitaxel uptake and transport in Taxus cell suspension cultures. Biochem Eng J 63:50-56. https://doi.org/10.1016/j.bej.2012.01.006

Nosov AM (2012) Application of cell technologies for production of plant-derived bioactive substances of plant origin. Appl Biochem Microbiol 48:609-624. https://doi.org/10.1134/S00036838110700 9X

Onrubia M, Cusidó RM, Ramirez K, Hernández-Vàzquez L, Moyano E, Bonfill M, Palazon J (2013a) Bioprocessing of plant in vitro systems for the mass production of pharmaceutically important metabolites: paclitaxel and its derivatives. Curr Med Chem 20:880-891. https://doi.org/10.2174/0929867311320070004

Onrubia M, Moyano E, Bonfill M, Cusidó RM, Goossens A, Palazón J (2013b) Coronatine, a more powerful elicitor for inducing taxane biosynthesis in Taxus media cell cultures than methyl jasmonate. J Plant Physiol 170:211-219. https://doi.org/10.1016/j.jplph .2012.09.004

Patil RA, Kolewe ME, Normanly J, Walker EL, Roberts SC (2012) Contribution of taxane biosynthetic pathway gene expression to observed variability in paclitaxel accumulation in Taxus suspension cultures. Biotechnol J 7:418-427. https://doi.org/10.1002/ biot. 201100183

Patil RA, Kolewe ME, Roberts SC (2013) Cellular aggregation is a key parameter associated with long term variability in paclitaxel accumulation in Taxus suspension cultures. Plant Cell Tissue Org Cult 112:303-310. https://doi.org/10.1007/s11240-012-0237-3

Patil RA, Lenka SK, Normanly J, Walker EL, Roberts SC (2014) Methyl jasmonate represses growth and affects cell cycle progression in cultured Taxus cells. Plant Cell Rep 33:1479-1492. https://doi.org/10.1007/s00299-014-1632-5

Pilarek M (2014) Liquid perfluorochemicals as flexible and efficient gas carriers applied in bioprocess engineering: an updated overview and future prospects. Chem Process Eng 35:463-487. https://doi. org/10.2478/cpe-2014-0035

Pilarek M, Szewczyk KW (2008) Effects of perfluorinated oxygen carrier application in yeast, fungi and plant cell suspension cultures. Biochem Eng J 41:38-42. https://doi.org/10.1016/j. bej.2008.03.004

Roberts SC, Naill M, Gibson DM, Shuler ML (2003) A simple method for enhancing paclitaxel release from Taxus canadensis cell suspension cultures utilizing cell wall digesting enzymes. Plant Cell Rep 21:1217-1220. https://doi.org/10.1007/s00299-003-0575-z

Russin W, Ellis D, Gottwald J, Zeldin EL, Brodhagen M, Everet RF (1995) Immunocytochemical Localization of Taxol in Taxus cuspidata. Int J Plant Sci 156:668-678. https://doi.org/10.1086/297289

Sabater-Jara AB, Tudela LR, López-Pérez AJ (2010) In vitro culture of Taxus sp.: strategies to increase cell growth and taxoid production. Phytochem Rev 9:343-356. https://doi.org/10.1007/s1110 $1-010-9167-z$

Sabater-Jara AB, Onrubia M, Moyano E, Bonfill M, Palazón J, Pedreño MA, Cusidó RM (2014) Synergistic effect of cyclodextrins and methyl jasmonate on taxane production in Taxus $\times$ media cell cultures. Plant Biotechnol J 12:1075-1084. https://doi.org/10.1111/ pbi. 12214

Strobel G, Sierle A, Hess WM (1993) Taxol formation in yew-Taxus. Plant Sci 92:1-12. https://doi.org/10.1016/0168-9452(93)90060 $-\mathrm{D}$

Syklowska-Baranek K, Pietrosiuk A, Kokoszka A, Furmanowa M (2009) Enhancement of taxane production in hairy root culture of Taxus $\times$ media var. Hicksii. J Plant Physiol 166:1950-1954. https://doi.org/10.1016/j.jplph.2009.05.001

Sykłowska-Baranek K, Grech-Baran M, Naliwajski MR, Bonfill M, Pietrosiuk A (2015a) Paclitaxel production and PAL activity in hairy root cultures of Taxus $\times$ media var. Hicksii carrying a taxadiene synthase transgene elicited with nitric oxide and methyl jasmonate. Acta Physiol Plant 37:1-9. https://doi.org/10.1007/ s11738-015-1949-x

Sykłowska-Baranek K, Pilarek M, Bonfill M, Kafel K, Pietrosiuk A (2015b) Perfluorodecalin-supported system enhances taxane production in hairy root cultures of Taxus $\times$ media var. Hicksii carrying a taxadiene synthase transgene. Plant Cell Tissue Organ Cult 120:1051-1059. https://doi.org/10.1007/s11240-014-0659-1

Talano MA, Wevar Oller AL, Gonzalez PS, Agostini E (2012) Hairy roots, their multiple applications and recent patents. Recent Pat Biotechnol 6:115-133. https://doi.org/10.2174/187220812801784 713

Theodoridis G, de Jong CF, Laskaris G, Verpoorte R (1998a) Application of SPE for the HPLC analysis of taxanes from Taxus cell cultures. Chromatographia 47:25-34. https://doi.org/10.1007/ BF02466782

Theodoridis G, Laskaris G, de Jong CF, Hofte AJP. Verpoorte R (1998b) Determination of paclitaxel and related diterpenoids in plant extracts by high-performance liquid chromatography with UV detection in high-performance liquid chromatography-mass 
spectrometry. J Chromatogr A 802:297-305. https://doi. org/10.1016/S0021-9673(97)01174-6

Vongpaseuth K, Roberts SC (2007) Advancements in the understanding of paclitaxel metabolism in tissue culture. Curr Pharm Biotechnol 8:219-236. https://doi.org/10.2174/138920107781387393

Wickremesinhe ERM, Arteca RN (1994) Taxus cell suspension cultures: optimizing growth and production of Taxol. J Plant Physiol 144:183-188. https://doi.org/10.1016/S0176-1617(11)80541-9

Wickremesinhe ERM, Arteca RN (1996) Effects of plant growth regulators applied to the roots of hydroponically grown Taxus $\times$ media plants on the production of taxol and related taxanes. Plant Sci 121:29-38. https://doi.org/10.1016/S0168-9452(96)04513-X

Wilson SA, Roberts SC (2012) Recent advances towards development and commercialization of plant cell culture processes for the synthesis of biomolecules. Plant Biotechnol J 10:249-268. https:// doi.org/10.1111/j.1467-7652.2011.00664.x
Wu J, Lin L (2003) Enhancement of taxol production and release in Taxus chinensis cell cultures by ultrasound, methyl jasmonate and in situ solvent extraction. Appl Microbiol Biotechnol 62:151-155. https://doi.org/10.1007/s00253-003-1275-x

Xu QM, Cheng JS, Ge ZQ, Yuan YJ (2005) Abnormal mitosis versus apoptosis of Taxus cuspidata induced by oleic acid in two-liquidphase suspension cultures. Enzyme Microb Technol 37:76-81. https://doi.org/10.1016/j.enzmictec.2005.01.035

Zhang C, Xu H (2001) Improved paclitaxel production by in situ extraction and elicitation in cell suspension cultures of Taxus chinensis. Biotechnol Lett 23:189-193. https://doi.org/10.1023/A:10056 55219649

Zhou M-L, Zhu X-M, Shao J-R, Tang Y-X, Wu Y-M (2011) Production and metabolic engineering of bioactive substances in plant hairy root culture. Appl Microbiol Biotechnol 90:1229-1239. https:// doi.org/10.1007/s00253-011-3228-0 